\title{
Nos (não) limites da palavra: movências do modo escrito de enunciação
}

\section{In the (non)limits of the word: movement of the written form of enunciation}

Cristiane Carneiro Capristano*

*Universidade Estadual de Maringá (UEM), Maringá, Paraná / Brasil capristano1@yahoo.com.br

http://orcid.org/0000-0003-1225-5716

Resumo: Este artigo expõe resultados de pesquisa cujo objetivo geral foi entender o que representava para a aquisição da escrita o aparecimento de segmentações não convencionais, resultantes de combinações entre separações e junções não previstas de palavras, em enunciados escritos por crianças. Especificamente, buscou-se compreender como essas segmentações funcionavam e descrever a emergência delas na primeira etapa do ensino fundamental (EF). O material foi constituído por 3.129 enunciados escritos, nos quais foram identificadas 321 segmentações, analisadas qualitativa e quantitativamente. A análise quantitativa permitiu verificar que essas segmentações são características do primeiro ciclo do EF. Por meio da análise qualitativa, averiguou-se que essas segmentações têm funcionamento complexo, resultante de um jogo entre irrupção e interrupção de práticas orais e letradas.

Palavras-chave: aquisição da escrita; escrita infantil; segmentação de palavras.

Abstract: This article presents the results of a research aimed to understand what the presence of non-conventional segmentations resulting from combinations of non-expected separations and juncture of words in statements written by children meant for written language acquisition. Specifically, it sought to comprehend how segmentations worked and describe their emergence during the first stage of elementary education (EE). Among the 3.129 written statements included in the research, 321 segmentations were identified and analyzed qualitatively and quantitatively. The quantitative analysis showed that these segmentations are characteristic to the first stage of $\mathrm{EE}$ and the qualitative analysis indicated their complex operation, arising from a game of irruption and interruption of oral and literate practices.

Keywords: written language acquisition; children's writing; words segmentation. 


\section{A segmentação da escrita da criança: problematizações}

Neste artigo, ${ }^{1}$ invisto em um objeto de pesquisa ao redor do qual se movimentam reflexões que tenho feito sobre a escrita da criança: sua segmentação. Do ponto de vista de seu funcionamento estritamente formal, a segmentação pode ser definida como um " [...] recurso ligado ao aspecto gráfico-visual do enunciado escrito que possibilita, de diferentes maneiras, a divisão do fluxo textual em porções menores [...]". (CAPRISTANO, 2007a, p. 2) Assim delimitado, esse recurso gráfico-visual recobriria, por exemplo, a pontuação, incluindo as marcas de paragrafação, o estabelecimento de fronteiras de palavras pelo emprego de espaços em branco etc.

Tenho investigado, sobretudo, como as fronteiras estabelecidas pelo emprego de espaços em branco relativos aos limites de palavra se mostram na escrita da criança. (CAPRISTANO, 2007a, 2007b, 2010 e 2013) Na escrita da criança, essas fronteiras nem sempre são as mesmas previstas pelas convenções ortográficas e, quando não convencionais, podem se manifestar no que as várias pesquisas sobre a segmentação da escrita da criança, desenvolvidas principalmente a partir da década de 1980 do século XX, têm chamado de hipossegmentação, hipersegmentação e mesclas/híbridos/mistos, como exemplificam os registros organizados no Quadro 1:

\footnotetext{
1 Apresento, neste artigo, parte dos resultados de pesquisa desenvolvida no período de 2016-2017, no âmbito das atividades do pós-doutorado do Programa de Pós-Graduação em Filologia e Ciências Humana da Faculdade de Filosofia, Letras e Ciências Humanas da USP, constituído via Programa Nacional de Pós-Doutorado da Capes (PNPD).

2 Algumas dessas pesquisas serão citadas ao longo deste artigo.
} 
Quadro 1 - Segmentação na escrita da criança

\begin{tabular}{|c|c|c|}
\hline Hipossegmentação & Hipersegmentação & Mesclas/Híbridos/Mistos \\
\hline Figura 1 - Hipossegmentação & \multirow{2}{*}{$\begin{array}{c}\text { Figura 3- } \\
\text { Hipersegmentação }\end{array}$} & Figura 5 -Mesclas/híbridos/mistos \\
\hline \multirow{3}{*}{ 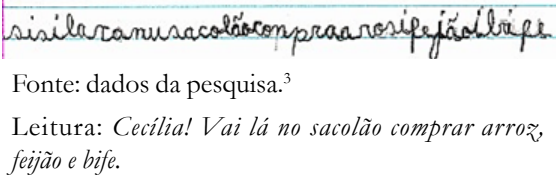 } & & SABENA DA MUTOE BET: \\
\hline & CAO PUTA & \multirow{2}{*}{$\begin{array}{l}\text { Fonte: dados da pesquisa. } \\
\text { Leitura: Sabe nada muito bem. }\end{array}$} \\
\hline & Fonte: dados da pesquisa. & \\
\hline \multirow[t]{2}{*}{ Figura 2 - Hipossegmentação } & $\begin{array}{c}\text { Figura } 4- \\
\text { Hipersegmentação }\end{array}$ & Figura 6 - Mesclas/híbridos/mistos \\
\hline & 1. & Fonte: dados da pesquisa. \\
\hline Fonte: dados da pesquisa. & Fonte: dados da pesquisa. & Leitura: Um quilo de asinba. \\
\hline Leitura: Na sala & Leitura: Essa música. & \\
\hline
\end{tabular}

Fonte: elaboração própria.

Hipossegmentações emergem, na escrita da criança, como junções não previstas de palavras, como em nasala. Hipersegmentações, por sua vez, se apresentam como separações não previstas de palavras, como em cão putado (computador). Mesclas/híbridos/mistos, segmentações, em geral, mais raras, se mostram como uma combinação entre separações e junções não previstas de palavras, como em um que lode azinha (um quilo de asinha). $\mathrm{Na}$ investigação da qual se origina este artigo, foram tomadas como objeto de pesquisa, com exclusividade, as segmentações não convencionais classificadas ora como mescla (CHACON, 2004; CAPRISTANO, 2007a, 2007b) ora como híbrido (CUNHA, 2010) ou, ainda, como misto. (PIACENTE; QUEREJETA, 2012)

Convém destacar, como adiantado em outro trabalho (CAPRISTANO, 2018), que a opção pela tríplice nomeação mesclas/híbridos/mistos é uma forma de manter e expor a flutuação com a qual esse tipo de fenômeno tem sido classificado e estudado nas pesquisas sobre a escrita da criança, flutuação ligada a diferenças teóricas e metodológicas entre as pesquisas. Essa opção é, também, uma forma de dar destaque à convergência entre essas nomeações, todas elas reconhecendo o caráter heterogêneo e complexo desses tipos especiais de segmentação

A eleição desse tipo de segmentação como objeto de pesquisa não é casual. As pesquisas sobre escrita da criança consideram mesclas/ 
híbridos/mistos como uma segmentação não possível de ser explicada de forma satisfatória se classificada, em separado, como episódios de hipossegmentação ou de hipersegmentação. São, portanto, "casos especiais", merecedores de classificações, descrições e explicações diferentes. Pesquisas como as de Cunha (2010) e de Chacon (2004), por exemplo, entendem que, nesses modos não convencionais de emprego dos espaços em branco, podem-se "[...] observar motivações relativamente iguais às que aparecem nas hipo e hipersegmentações" (CUNHA, 2010, p. 347, grifo meu). Esses dados parecem, também, em alguns momentos, não reproduzir - como nos casos de hiper e hipossegmentação - “[ ...] padrões rítmico-entonacionais da oralidade e/ou que não se explicam com base em algoritmos como aqueles que definem constituintes da hierarquia prosódica, conforme proposta por Nespor e Vogel (1986)". (CHACON, 2004, p. 225) Ou seja, identificam-se convergências e divergências entre o funcionamento de mesclas/híbridos/ mistos quando comparado ao de hipo e hipersegmentações.

Embora as pesquisas sobre segmentação da escrita da criança tenham chamado a atenção para esses casos especiais de segmentação, não há, ainda, no conjunto desses trabalhos, uma efetiva descrição dessas segmentações, ou seja, ainda não tem sido explorado de forma profícua como ocorre a emergência de mesclas/híbridos/mistos na escrita da criança. Ademais, não há uma problematização satisfatória do seu funcionamento, uma vez que os debates ainda não contemplaram, com exclusividade, o que essas segmentações especiais representariam para o funcionamento da escrita da criança. Essas faltas e a convicção de que a segmentação da escrita da criança não é tema esgotado - nem quando se trata da descrição dos processos mostrados quando as crianças segmentam, nem quando se trata das consequências dessa descrição para entender o funcionamento da escrita da criança - são os motivos pelos quais se justifica a pesquisa proposta.

Trabalhando na área de ensino-aprendizagem de línguas e no campo dos estudos sobre a escrita (em especial, sobre a escrita da criança), tendo como ponto de partida um olhar transdisciplinar (SERRANI, 1990; SIGNORINI; CAVALCANTI, 1998) e como eixo organizador contribuições advindas, principalmente, do campo dos estudos da enunciação e do discurso, ${ }^{3}$ a pesquisa tem como objetivo geral entender o que esse tipo

\footnotetext{
3 Como destacado também em Capristano (2018), esta pesquisa esteve fundamentada em reflexões do quadro não homogêneo composto pelas Teorias da Enunciação (particularmente,
} 
bastante particular de segmentação não convencional poderia representar para a escrita da criança e, consequentemente, para a chamada aquisição da escrita. Para alcançar esse objetivo geral, buscou-se, de forma específica, (1) compreender como funcionam essas segmentações e (2) descrever como ocorre sua emergência no período de escolarização correspondente à primeira etapa do ensino fundamental. A pesquisa, de caráter longitudinal, foi desenvolvida a partir de um material constituído por 3.129 enunciados escritos, coletados em duas escolas públicas da rede municipal de ensino de uma cidade no interior paulista. Esse material será apresentado com mais detalhes em seção subsequente.

Visando a finalidade de apresentar os principais resultados alcançados pela pesquisa, este artigo está organizado da seguinte maneira: na primeira seção, para responder ao primeiro objetivo específico, busca-se mostrar como funcionam as segmentações nomeadas como mesclas/híbridos/mistos, por meio de uma análise qualitativa dos dados levantados na pesquisa. $\mathrm{Na}$ segunda seção, na busca por responder ao segundo objetivo específico, são discutidos os resultados quantitativos, por meio dos quais se mostra como mesclas/híbridos/mistos emergem em enunciados escritos de crianças na primeira etapa do ensino fundamental (daqui em diante, EF-I). Nessa mesma seção, o material de análise e os procedimentos metodológicos empregados para a execução da dimensão quantitativa da pesquisa são descritos. Por fim, propõe-se uma conclusão para as reflexões, discutindo o impacto e as possíveis contribuições da pesquisa para o campo de saberes no qual se inscreve.

\section{Mesclas/híbridos/mistos: pistas de movências do modo de enunciação escrito}

Nas pesquisas sobre segmentação da escrita, feitas a partir de diferentes enquadramentos teórico-metodológicos e com diferentes objetivos, se encontram informações sobre a já comentada raridade da emergência de mesclas/híbridos/mistos na enunciação escrita da criança. Cunha (2010), por exemplo, em estudo semi-longitudinal sobre a relação entre segmentações não convencionais e constituintes prosódicos

a de Benveniste, reinterpretada, a de Bakhtin e o Círculo e a de Authier-Revuz), pela Pragmática e pela Análise do Discurso Francesa, numa leitura que se pretende mais próxima desta última, aderindo à direção aberta em Corrêa (2001, 2004, 2006, 2007, 2011, 2013). 
(NESPOR; VOGEL, 1986), feito a partir da análise de produções textuais de crianças brasileiras (à época, cursando o EF-I), mostra que, quando comparadas às hipossegmentações e às hipersegmentações, mesclas / híbridos/mistos são muito pouco frequentes nas produções textuais infantis, tanto no contexto da escola pública, quando no da particular, analisados por ela, como comprovado pelos dados do gráfico 1, organizados pela autora:

Gráfico 1 - Segmentação na escrita da criança

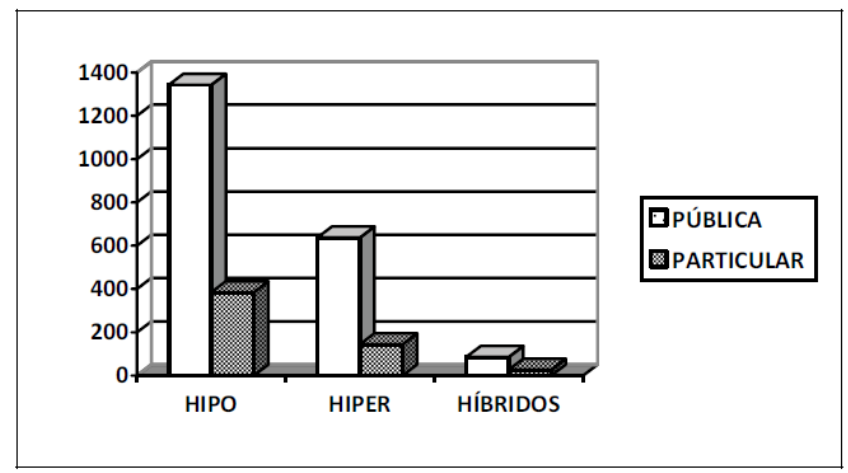

Fonte: CUNHA, 2010, p. 331.

Resultado semelhante pode ser encontrado em Piacente e Querejeta (2012) e Capristano (2007b), pesquisas nas quais, no âmbito de outras discussões, também foram feitas comparações iniciais entre a emergência de mesclas/híbridos/mistos e hipo e hipersegmentações. O primeiro trabalho é um estudo transversal-correlacional, no qual foram examinadas as características, a ocorrência e a persistência de segmentações não convencionais em textos e sentenças produzidas por crianças argentinas, em diferentes níveis de escolaridade. O segundo refere-se a um estudo longitudinal com duas crianças brasileiras, cuja finalidade foi investigar como se davam as mudanças na trajetória da criança e da sua escrita com relação à segmentação de palavras.

Nas pesquisas sobre segmentação da escrita da criança - aqui exemplificadas pelos trabalhos supracitados -, a constatação da raridade e infrequência de mesclas/híbridos/mistos vem acompanhada de intuições sobre a complexidade do funcionamento desse tipo invulgar de segmentação. Como adiantado, essas pesquisas consideram mesclas/híbridos/mistos como um tipo de segmentação especial e argumentam não ser possível 
explicá-lo de forma satisfatória se ele for considerado em separado, como mero caso de hipossegmentação ou de hipersegmentação. Ou seja, numa ocorrência como a da Figura 7, não bastaria entender, de um lado, as motivações para a emergência da separação entre "e" e "la", no registro de ela e, de outro, as da junção entre "ela" e "sabe", no registro de ela sabe nadar. A convicção é a de que, nesses casos, se está diante de um funcionamento mais complexo da segmentação, só possível de ser compreendido em sua totalidade se consideradas em conjunto e correlacionadas as separações e junções feitas pelas crianças.

Figura 7 - Mesclas/híbridos/mistos

um lelè í laraber nadar

Fonte: dados da pesquisa.

A análise qualitativa e longitudinal de mesclas/híbridos/mistos presentes no material que serviu de base para a pesquisa apresentada neste artigo permitiu sustentar essa convicção: os 321 mesclas/híbridos/mistos identificados nos 3129 enunciados escritos são, de fato, ocorrências complexas de segmentação, como exemplificam os enunciados a seguir, nas figuras 8 e 9 .

Figura 8 - Mosquito da dengue



Fonte: dados da pesquisa. ${ }^{4}$

${ }^{4}$ Leitura (as barras duplas indicam mudança de linha): São José do Rio 22 de agosto $\mathrm{de} / / 2001 / /$ Nome// Mosquito da dengue//tome cuidado com o mosquito da dengue, [vo]cê pode ter// muita doença e muita criança pode [trecho não legível] pode ir// para 
No enunciado da Figura 8, a presença e a ausência de espaços em branco (previstos e nãow previstos pelas convenções ortográficas) no cabeçalho são acompanhadas de traços sublinhando os limites do que se pode supor que a criança considerou como unidades. Esse gesto aparecia comumente na escrita das crianças da sala de aula na qual esse enunciado emergiu (mais adiante identificada como escola 1), nos diferentes momentos durantes as aulas nas quais elas registravam o cabeçalho, por meio de cópia direta da lousa ou por iniciativa própria. Tratava-se de uma prática lúdica, usada pela professora da sala para justamente mostrar as unidades que, convencionalmente, deveriam ser separadas por branco, prática retomada por várias das crianças participantes da atividade de coleta geradora dos enunciados aqui examinados.

No modo como a criança sublinha o cabeçalho - que pode ou não ter sido copiado da lousa ${ }^{5}$ - e distribui os espaços em branco, é possível ver que essa prática é atravessada por outras, uma vez que as unidades reconhecidas, sublinhadas e delimitadas por brancos por essa criança não são exatamente as mesmas da professora e parecem resultar justamente da circulação da criança por outras práticas. ${ }^{6}$ A segmentação não convencional resultante

o hospital e o mosquito da dengue faz muitas pessoas/ / fica[rem] doentes e tome cuidado [trecho não legível]// imagina se o mosquito da dengue e causa mui//ta febre.

${ }^{5}$ Não existem informações no arquivo de produções textuais do qual esse enunciado faz parte se, no dia da coleta, havia ou não um cabeçalho exposto na lousa ou em outro lugar da sala de aula onde eram feitas as coletas para que as crianças pudessem copiar. Para os propósitos desta análise, a ausência dessa informação não é relevante, uma vez que interessa entender a atualização dessa prática não no plano empírico, mas no plano da recuperação do "já-vivido" e/ou do "já-experimentado", que pode ou não ocorrer por meio de uma cópia. Vê-se, assim, que, aqui, a cópia é entendida como uma atividade não mecânica.

${ }^{6}$ Essa circulação por práticas orais e letradas, no que toca à segmentação por espaços em branco delimitadores de palavras gráficas, poderia também ser visualizada no contraste entre a segmentação proposta no cabeçalho e a segmentação do restante desse enunciado. Com exceção dos espaços em branco presentes no início e no final do título, no início e no final do que se poderia chamar de "corpo do texto" e, por fim, na terceira linha do "corpo do texto" - onde é possível observar uma rasura (apagamento) -, não há indícios de que os espaços em branco separem unidades maiores do que as letras - parece, em vez disso, que o "corpo do texto" foi registrado quase num único fluxo. Essa discussão, no entanto, foge ao escopo da pesquisa apresentada neste artigo. 
desse sublinhado e dessa delimitação por brancos caracteriza-se, por um lado, por separações convencionais - delimitação das fronteiras iniciais e finais dos números (22 e 2001), delimitação da fronteira inicial de de em *dea gostode e delimitação da fronteira final de de em dea gostode* * e, por outro, por uma combinação entre uma junção (dea gosto), uma separação (dea gostode) e, novamente, uma junção (gostode) não previstas no que se poderia supor ser uma mesma sequência (22 de agosto de 2001). Essas junções e separações mostram:

(a) a criança sob o efeito da possibilidade de "22DEAGOSTODE (translineação) 2001" ser uma unidade - projeto que, se plenamente efetivado, resultaria em uma hipossegmentação -, em razão da atuação do contorno rítmico e entonacional do que pode ser interpretado como uma frase entonacional (hipótese fundada nas junções não convencionais e baseada na proposta de CHACON, 2004): [[São José do Rio Preto]I [22 DE*A GOSTO $==D E$ 2001]I] $\mathrm{U}^{7}$

(b) a criança sob o efeito da possibilidade de 22 e 2001, por serem números e não letras, serem unidades - no segundo caso, possibilidade permitida também pelo co-texto de translineação (São José do Rio Preto, 22 DEA GOSTODE (translineação) 2001).

(c) a criança sob o efeito da possibilidade de um processo de ressilabação: em de agosto, existe contexto para a emergência do processo de ditongação, o qual se refere à formação de ditongos pela junção da vogal final de um vocábulo (de) com a inicial de outro (agosto), junção que ocorre desde que uma das vogais da sequência seja alta e átona - como é o caso da vogal representada pelo grafema E, em "de", pronunciado como /i/ na variante linguística falada pelas crianças cujos enunciados foram aqui examinados.

\footnotetext{
7 Na proposta de Nespor e Vogel (1986), a frase entonacional é um constituinte formado por um conjunto de frases fonológicas $(\Phi)$ ou apenas uma frase fonológica, portadora de informação entonacional. Suas fronteiras coincidem com posições nas quais podem ser introduzidas pausas. Para Bisol (1996), existem duas características básicas para a identificação de uma frase entonacional: (1) em uma sequência de frases fonológicas que constituam uma frase entonacional, uma delas será sempre forte, por características semânticas, e todas as demais serão fracas; (2) uma sentença - declarativa, exclamativa ou interrogativa - tem um contorno entonacional determinado, embora, no interior destas unidades, sempre possa haver certa flexibilidade. Para mais informações, consultar Nespor e Vogel (1986) e Bisol (1996).
} 
(d) a criança sob o efeito da possibilidade de, prospectivamente, dea mostrar-se como uma unidade, ao mesmo tempo, fônica (um dissílabo paroxítono que, do ponto de vista prosódico, se estrutura ritmicamente como um pé troqueu) e gráfica autônoma - numa relação de semelhança parcial com a palavra dia (substantivo masculino singular) - São José do Rio Preto, 22 dea gostode 2001.

(e) a criança sob o efeito da possibilidade de, retrospectivamente, a sílaba inicial de agosto mostrar-se como uma unidade fônica (uma sílaba) e gráfica autônoma - numa relação homonímica com a (artigo feminino singular) - e de (gostode) mostrar-se como uma unidade fônica (uma sílaba) e gráfica autônoma (como de fato é); São José do Rio Preto, 22 dea gostode 2001.

(f) a criança sob o efeito da possibilidade de, prospectivamente, gosto mostrar-se como uma unidade, ao mesmo tempo, fônica (um dissílabo paroxítono que, do ponto de vista prosódico, se estrutura ritmicamente como um pé troqueu) - numa relação homonímica com gosto (verbo ou nome): São José do Rio Preto, 22 dea gostode 2001.

O mesmo funcionamento complexo pode ser visto na Figura 9. Nessa figura, a segmentação damedicament ounan (dar medicamento ou não) caracteriza-se, por um lado, por delimitações convencionais - da fronteira inicial de *da, da fronteira final de não* - e, por outro, por uma combinação entre junções (damedicament ounan) e uma separação (damedicament* ounan) não previstas.

Figura $9-\mathrm{O}$ ouvido

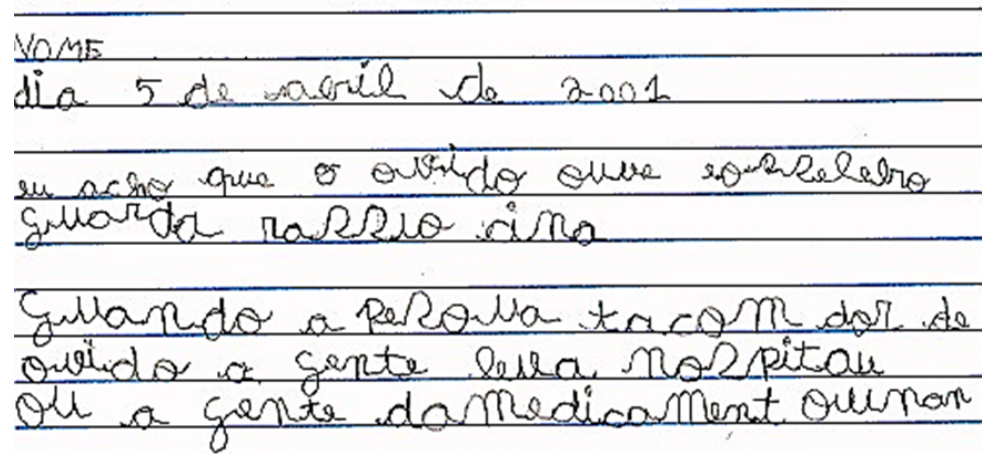

Fonte: dados da pesquisa. ${ }^{8}$

8 Leitura (as barras duplas indicam mudança de linha): Nome// Dia 5 de abril de 2001// 
As junções e separações em damedicament ounan ocorrem no âmbito do que se poderia supor ser a fronteira entre duas frases entonacionais presentes no enunciado fonológico [Ou a gente dá medicamento ou não] U, ${ }^{9}$ assim, organizadas: [[Ou a gente]I [da medicamento] I [ou não]]] U. Nessa organização, supõem-se poder existir, na produção falada desse enunciado, a topicalização de "ou a gente", com a estruturação, subsequente, de duas frases entonacionais, que constituem, do ponto de vista semântico, duas alternativas para tratar a pessoa "que está com dor de ouvido". Nas junções não previstas - entre "da" e "medicamento" e entre "ou" e "não" -, são justamente as fronteiras (direita e esquerda) dessas frases entonacionais que atuam para a emergência dessas segmentações não convencionais. A separação não convencional em damedicament ounan provoca, por sua vez, uma segmentação pouco comum na escrita de crianças, na qual é rompida, ainda que apenas do ponto de vista gráfico, a estrutura da sílaba. Nessa ruptura incomum, a criança parece estar sob o efeito de como representar graficamente, por um lado, a ambissilabicidade da vogal "o" e, por outro, um contexto gráfico complexo envolvendo uma sequência de duas vogais idênticas.

Na produção falada do enunciado fonológico [Ou a gente dá medicamento ou não]U, a vogal "o" tem comportamento ambissilábico, ou seja, ao mesmo tempo em que aparece na parte final do núcleo silábico da palavra "medicamento", também ocupa a posição de início da sílaba seguinte ("ou"), como mostra o esquema a seguir: ${ }^{10}$

Eu acho que o ouvido ouve e o celebro//Guarda, raciocina//Quando a pessoa [es]tá com dor de// ouvido a gente leva no hospital// Ou a gente da medicamento, ou não.

9 De acordo com Nespor e Vogel (1986), o enunciado fonológico (U) é o constituinte mais alto da hierarquia prosódica e é composto de uma ou mais frases entonacionais. Sua delimitação de suas fronteiras é feita pela identificação do começo e do fim de um constituinte oracional de natureza sintático-semântica e/ou, também, por pausas.

${ }^{10}$ A sílaba é descrita neste artigo da perspectiva de Selkirk (1982), como interpretada por Chacon (no prelo). Nessa perspectiva, a sílaba é uma “[...] unidade que estrutura seus constituintes de maneira hierarquizada.”. Ela se organiza em constituintes, sendo os principais o ataque (onset) e a rima. Ataque e rima podem se ramificar, respeitando a hierarquia possível de cada língua, como mostra o esquema a seguir, no qual se exemplifica 
Figura 10 - Sílabas "to" e "ou”



Fonte: elaboração própria.

Por sua vez, na produção gráfica de ou a gente dá medicamento ou não, a complexidade se instala na necessidade de registro de dois grafemas idênticos em sequência. Ferreiro e Teberosky (1979), em seus trabalhos sobre a psicogênese da escrita, em especial na discussão do que ficou conhecida como etapa "pré-silábica", argumentam existir, na gênese da escrita, um período (pré-silábico) no qual as concepções das crianças sobre escrever seriam atravessadas por critérios de distinção tanto intrafigurais (quantidade mínima de letras e variação interna das letras de um segmento) quanto interfigurais (quantidade mínima de letras e variação interna das letras entre segmentos). Assim, segundo as autoras, embora, nesse período, as crianças ainda não escrevam com base no princípio alfabético da escrita, suas concepções já supõem critérios de diferenciação. Ainda que, neste artigo, não se trate nem

essa organização hierárquica a partir da descrição da sílaba inicial da palavra "grande" esquema recolhido de Chacon (no prelo):

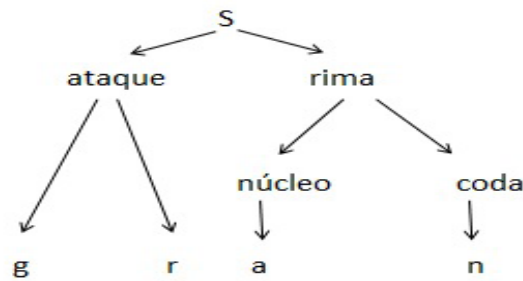


desse período, nem se veja a aquisição da escrita sob essa perspectiva, pode-se afirmar ser a necessidade de distinções intra e interfigurais que atua também para a emergência dessa segmentação não convencional.

Com a análise qualitativa de segmentações como as exemplificadas pelas Figuras 8 e 9, foi possível responder ao primeiro objetivo específico da pesquisa, ou seja, foi possível compreender melhor como funcionam as segmentações chamadas de mesclas/híbridos/mistos. Além de terem funcionamento complexo, mesclas/híbridos/mistos resultam, como intuído por Cunha (2010, p. 347), de um "[...] jogo de influências de diferentes aspectos linguísticos [...]", mostrado, quase sempre, pela interrupção de práticas orais e letradas e, ao mesmo tempo, pela irrupção de outras práticas orais e letradas, entendidas aqui como experiências sócio-históricas que chegam a criança como memórias (já ditos, já ouvidos, já lidos, já vistos e já escritos). De um ponto de vista enunciativo-discursivo, tenho entendido "memória" como sendo "[...] um espaço móvel de divisões, de disjunções, de deslocamentos e de retomadas, de conflitos de regularização [...] Um espaço de desdobramentos, réplicas, polêmicas e contra-discursos". (PÊCHEUX, 1997, p. 56)

Tendo como fundamento e norte a reflexão de Chacon (2017), creio ser possível afirmar também que esse jogo entre irrupção e interrupção de práticas orais e letradas, exposto na superfície plana da escrita, na folha de papel, projeta a criança como deslizando por uma realidade plástica e multidimensional, composta por práticas entrecruzadas, de forma não planificada, assimétrica, num movimento inevitável de deriva e de dispersão dos sentidos e, correlativamente, num movimento inevitável de deriva e de dispersão permitido pela própria língua, em sua estruturação simbólica. Como fruto dessa projeção, no entanto, não se vê, a forma de um espelho, essa realidade multidimensional e plástica, mas sinais de seu funcionamento e, sobretudo, do modo particular e idiossincrático por meio do qual a criança é capturada por ela, inscrita nela. Mesclas/híbridos/mistos são, nesse sentido, pistas das movências de sentidos e da própria língua atuantes na enunciação escrita da criança, movências que, no enquadramento teórico do qual parte a presente pesquisa, são permitidas pelos sempre complexos e inéditos encontros entre o eu e outro, constitutivos desse modo de enunciação.

Esse funcionamento de mesclas/híbridos/mistos permite interrogar se esse tipo especial de segmentação não colocaria em relevo uma característica importante de todas as segmentações feitas pelas crianças 
em seus enunciados escritos: o fato de elas constituírem pistas dos modos a partir dos quais a criança conecta-se com o(s) sentido (s) e com a ordem própria da língua que lhe chegam no momento da enunciação escrita.

Dito de outro modo, a análise qualitativa das mesclas/híbridos/ mistos, apenas resumidamente apresentada aqui, permite defender que essas segmentações raras e especiais são sinais de que as crianças segmentam seus enunciados escritos não exatamente sob o efeito da busca por recortar palavras, mas, sim, sob o efeito da busca por recortar diferentes dimensões de suas experiências sócio-históricas, ou, ainda, da busca por encontrar sentidos para a (sua) escrita. Seriam, portanto, assim como todas as segmentações convencionais e não convencionais vistas na escrita de crianças, manifestações de como a língua e a escrita se mostram, se colocam ou se impõem ao sujeito e, ao mesmo tempo, marcas do sujeito na busca de alçar-se e/ou encontrar-se com sentidos da/para a (sua) escrita.

\section{Mesclas/híbridos/mistos: emergência ao longo do EF-I}

Nesta seção, como antecipado, busca-se responder ao segundo objetivo específico da pesquisa: descrever como ocorre a emergência de mesclas/híbridos/mistos no período de escolarização correspondente à primeira etapa do Ensino Fundamental. Para investigar essa emergência, foram tomados como material de análise enunciados escritos produzidos por crianças e organizados em um arquivo. ${ }^{11}$ Esses enunciados foram coletados no período de abril de 2001 a dezembro de 2004, em duas escolas da rede municipal de ensino de uma cidade no interior paulista, nomeadamente, São José do Rio Preto (SP). Na ocasião da coleta, foi acompanhado um mesmo grupo de crianças da (antiga) primeira à (antiga) quarta série do EFI, em duas escolas da rede pública de ensino que atendiam prioritariamente crianças de classes populares. A coleta ocorreu em intervalos quinzenais.

Nessas coletas, eram propostas, pela pesquisadora responsável, atividades de produção textual. Essas atividades sempre envolviam diferentes gêneros discursivos (cartas, piadas etc.). Foram propostas 55 atividades de produção textual. A coleta teve início contando com a participação de

\footnotetext{
${ }^{11}$ Esse arquivo tem subsidiado pesquisas de integrantes do Grupo de Pesquisa "Estudos sobre a linguagem" (CNPq), do qual participo, e do Grupo de Pesquisa "Estudos sobre a aquisição da escrita" (CNPq), do qual sou líder.
} 
71 crianças. Esse número foi, ao longo do tempo, alterado: por um lado, algumas crianças mudaram de período, classe e/ou escola e deixaram de participar das atividades; e, por outro, outras crianças começaram a participar das coletas em virtude de passarem a frequentar as salas de aula em que as produções textuais para constituição do arquivo eram recolhidas. $\mathrm{O}$ arquivo dispõe hoje de 3.129 enunciados escritos de 130 crianças, em diferentes momentos da aquisição da (sua) escrita. Esses dados estão organizados por sujeito, por escola e por ano. Eles também estão digitalizados e digitados, condições que facilitaram a análise do material.

Cabe, aqui, um adendo sobre a pertinência de explorar um material que, à primeira vista, poderia ser considerado antigo - uma vez que o arquivo de produções textuais foi constituído e tem sido explorado ao longo de mais de uma década. Essa pertinência liga-se a vários fatores, dentre os quais se destacam: (a) as condições ótimas e singulares de descrição e de explicação do funcionamento da escrita da criança proporcionadas pelo material organizado no arquivo de produções textuais (não encontradas, por exemplo, em coletas transversais e semi longitudinais, bem mais comuns nas pesquisas sobre a escrita da criança), condições que podem ser verificadas no fato de a coleta do material, de caráter longitudinal, ter sido feita por um mesmo pesquisador ao longo de quatro anos, com intervalos curtos entre as coletas (por volta de 15 dias) e com um grupo de criança que se manteve mais ou menos o mesmo ao longo desse tempo; e (b) a natureza do arquivo de produções textuais - construído a partir de variadas propostas de produção textual, realizadas por crianças em momentos diversos do processo de escolarização - que permite diferentes tipos de pesquisa, feitas pelos mesmos ou por diferentes pesquisadores. Na pesquisa, foram examinados todos os enunciados do arquivo.

Embora não tenha sido um dos objetivos iniciais da pesquisa, para a análise quantitativa dos dados, foram consideradas variáveis como o ano de coleta, proposta e grupo pesquisado (Escola 1 e Escola 2). A consideração dessas variáveis se mostrou importante para a organização da análise.

$\mathrm{Na}$ Tabela 1, é mostrada a distribuição dos enunciados considerados para a análise por escola e por ano - nessa e nas demais tabelas apresentadas neste artigo, P refere-se à proposta de produção textual; $\mathrm{A}(1,2,3,4)$ referese ao ano de coleta; E1 refere-se à escola 1; E2 à escola 2; TE ao total por escola e por ano; TA ao total geral por ano e, por fim, TG, na Tabela 1, ao total de enunciados examinados: 
Tabela 1 - Distribuição dos enunciados por ano e por escola

\begin{tabular}{c|c|c|c|c|c|c|c|c|c|c|c}
\hline \multicolumn{3}{c}{ A-1 } & \multicolumn{3}{c|}{ A-2 } & \multicolumn{3}{c|}{ A-3 } & \multicolumn{3}{c}{ A-4 } \\
\hline $\mathrm{P}$ & E1 & E2 & $\mathrm{P}$ & E1 & E2 & $\mathrm{P}$ & $\mathbf{E 1}$ & $\mathbf{E 2}$ & $\mathrm{P}$ & E1 & E2 \\
\hline 1 & 35 & 35 & 15 & 31 & 33 & 30 & 29 & 29 & 42 & 32 & 21 \\
2 & 32 & 33 & 16 & 34 & 35 & 31 & 30 & 24 & 43 & 34 & 17 \\
3 & 34 & 33 & 17 & 33 & 32 & 32 & 28 & 28 & 44 & 31 & 18 \\
4 & 31 & 32 & 18 & 33 & 33 & 33 & 29 & 28 & 45 & 15 & 16 \\
5 & 33 & 29 & 19 & 31 & 30 & 34 & 28 & 17 & 46 & 28 & 16 \\
6 & 33 & 27 & 20 & 33 & 34 & 35 & 31 & 30 & 47 & 31 & 17 \\
7 & 32 & 31 & 21 & 33 & 34 & 36 & 30 & 30 & 48 & 31 & 16 \\
8 & 33 & 33 & 22 & 30 & 33 & 37 & 31 & 30 & 49 & 27 & 17 \\
9 & 33 & 29 & 23 & 27 & 31 & 38 & 30 & 29 & 50 & 30 & 15 \\
10 & 34 & 31 & 24 & 33 & 33 & 39 & 29 & 30 & 51 & 29 & 12 \\
11 & 33 & 29 & 25 & 29 & 33 & 40 & 30 & 26 & 52 & 32 & 16 \\
12 & 27 & 30 & 26 & 28 & 32 & 41 & 31 & 27 & 53 & 27 & 12 \\
13 & 31 & 26 & 27 & 33 & 35 & & & & 54 & 26 & 13 \\
14 & 29 & 18 & 28 & 31 & 31 & & & & 55 & 30 & 16 \\
- & - & - & 29 & 31 & 25 & & & & & & 22 \\
TE & 450 & 416 & TE & $\mathbf{4 7 0}$ & 484 & TE & 356 & 328 & TE & 403 & $\mathbf{2 2 2}$ \\
TA & & $\mathbf{8 6 6}$ & TA & & $\mathbf{9 5 4}$ & TA & & $\mathbf{6 8 4}$ & TA & & $\mathbf{6 2 5}$ \\
TG & & & & & & & & & & & $\mathbf{3 1 2 9}$ \\
\hline
\end{tabular}

Fonte: elaboração própria

Como é possível observar pela Tabela 1, os enunciados considerados para análise estavam distribuídos de forma relativamente desigual entre os anos pesquisados $-27,4 \%$ no primeiro ano, $30,2 \%$ no segundo ano, $22,6 \%$ no terceiro ano e $19,8 \%$ no quarto ano. O segundo e o primeiro ano, respectivamente, são os que concentram o maior número de enunciados. Nesse material, foram identificados, primeiramente, todos os enunciados com e sem ocorrências de segmentação não convencional que deveriam e/ ou poderiam ser classificadas como mesclas/híbridos/mistos. Foi possível averiguar que dos 3159 enunciados examinados, apenas $189(6 \%)$ continham mesclas/híbridos/mistos, fato que comprova a raridade do aparecimento desse tipo de fenômeno. A Tabela 2 e o gráfico 2 sintetizam esse achado distribuído ao longo dos anos: 
Tabela 2 - Quantidade de enunciados com e sem mesclas/híbridos/mistos

\begin{tabular}{c|c|c|c|c|c|c|c|c|c}
\hline & A-1 & A-1 & A-2 & A-2 & A-3 & A-3 & A-4 & A-4 & \\
\cline { 2 - 8 } & SEM & COM & SEM & COM & SEM & COM & SEM & COM & T \\
\cline { 2 - 8 } E1 & 407 & 43 & 449 & 21 & 352 & 4 & 399 & 4 & $\mathbf{1 6 7 9}$ \\
E2 & 358 & 58 & 434 & 50 & 322 & 6 & 219 & 3 & $\mathbf{1 4 5 0}$ \\
T & $\mathbf{7 6 5}$ & $\mathbf{1 0 1}$ & $\mathbf{8 8 3}$ & 71 & $\mathbf{6 7 4}$ & $\mathbf{1 0}$ & $\mathbf{6 1 8}$ & 7 & $\mathbf{3 1 2 9}$ \\
\hline
\end{tabular}

Fonte: elaboração própria.

Gráfico 2 - Distribuição dos enunciados com e sem mesclas/híbridos/mistos

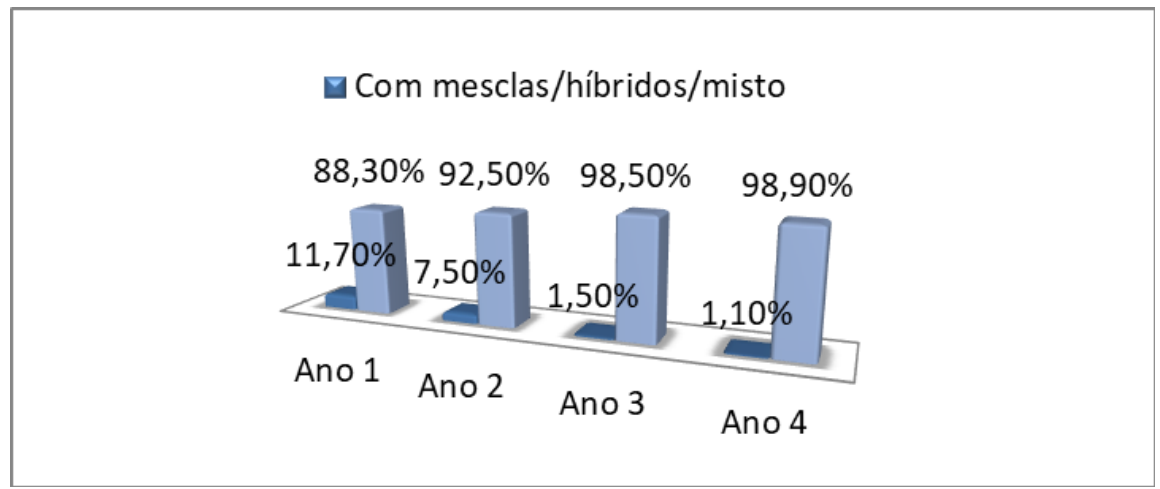

Fonte: elaboração própria.

A Tabela 2 e o gráfico 2 permitem ver que a maior concentração de enunciados com a presença de mesclas/híbridos/mistos ocorre no primeiro e no segundo ano de coleta (respectivamente, $11,7 \%$ e 7,5\%). Além disso, ambos colocam em cena algo já apontado pelas pesquisas sobre segmentação na escrita da criança: a raridade da emergência desse tipo de segmentação. Os dados obtidos na pesquisa deixam ver que são poucos os enunciados nos quais se vê emergir esse tipo especial de segmentação, sobretudo quando considerados os anos finais da primeira etapa do EFI. Feitas essas constatações, a análise voltou-se de forma pormenorizada para as ocorrências de mesclas/híbridos/mistos. Na Tabela 3 e no gráfico 3 , apresento a distribuição desses dados, considerando, novamente, a divisão por proposta, escola e ano de coleta - na Tabela 3, TME refere-se à quantidade de mesclas/híbridos/mistos por escola; TMA à quantidade de mesclas/híbridos/mistos por ano pesquisado; e, por fim, TMG à quantidade geral de mesclas/híbridos/mistos identificados: 
Tabela 3 - Quantidade de mesclas/híbridos e mistos identificados

\begin{tabular}{|c|c|c|c|c|c|c|c|c|c|c|c|}
\hline \multicolumn{3}{|c|}{ A-1 } & \multicolumn{3}{|c|}{ A-2 } & \multicolumn{3}{|c|}{ A-3 } & \multicolumn{3}{|c|}{ A-4 } \\
\hline P & $\begin{array}{l}\text { E1 } \\
\text { (S) }\end{array}$ & $\mathrm{E} 2$ & $\mathrm{P}$ & E1 & E2 & $\mathrm{P}$ & E1 & E2 & P & E1 & E2 \\
\hline 1 & 1 & 1 & 15 & 6 & 7 & 30 & 1 & 0 & 42 & 0 & 0 \\
\hline 2 & 4 & 3 & 16 & 9 & 11 & 31 & 2 & 3 & 43 & 0 & 0 \\
\hline 3 & 9 & 7 & 17 & 2 & 7 & 32 & 0 & 0 & 44 & 0 & 0 \\
\hline 4 & 3 & 9 & 18 & 2 & 13 & 33 & 0 & 1 & 45 & 1 & 0 \\
\hline 5 & 9 & 11 & 19 & 1 & 2 & 34 & 0 & 1 & 46 & 0 & 0 \\
\hline 6 & 9 & 15 & 20 & 0 & 4 & 35 & 1 & 1 & 47 & 0 & 0 \\
\hline 7 & 6 & 3 & 21 & 0 & 13 & 36 & 0 & 0 & 48 & 0 & 0 \\
\hline 8 & 6 & 12 & 22 & 0 & 3 & 37 & 0 & 0 & 49 & 0 & 0 \\
\hline 9 & 2 & 7 & 23 & 2 & 12 & 38 & 0 & 0 & 50 & 0 & 1 \\
\hline 10 & 5 & 2 & 24 & 5 & 17 & 39 & 2 & 0 & 51 & 1 & 0 \\
\hline 11 & 3 & 1 & 25 & 1 & 4 & 40 & 0 & 1 & 52 & 0 & 1 \\
\hline 12 & 10 & 2 & 26 & 0 & 4 & 41 & 0 & 0 & 53 & 0 & 0 \\
\hline 13 & 9 & 16 & 27 & 1 & 3 & & & & 54 & 0 & 0 \\
\hline 14 & 0 & 3 & 28 & 0 & 2 & & & & 55 & 2 & 1 \\
\hline- & - & - & 29 & 1 & 1 & & & & & & \\
\hline TME & 76 & 92 & TME & 30 & 103 & TME & 6 & 7 & TME & 4 & 3 \\
\hline TMA & & 168 & TMA & & 133 & TMA & & 13 & TMA & & 7 \\
\hline TMG & & & & & & & & & & & 321 \\
\hline
\end{tabular}

Fonte: elaboração própria.

Gráfico 3 - Distribuição de mesclas/híbridos/mistos por ano de coleta $\square$ Ano $1 \square$ Ano $2 \square$ Ano $3 \square$ Ano 4

$52,33 \%$

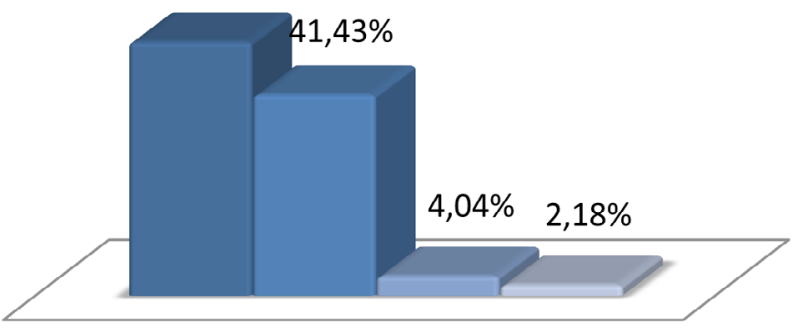

Mesclas/híbridos/mistos

Fonte: elaboração própria. 
A fim de verificar se essas diferenças eram estatisticamente significativas, os dados foram avaliados a partir de dois testes (t) e (z), com os quais pretendia-se testar as hipóteses: (1) H0: Média do ano 1 = Média do ano 2, ou seja, a média do ano 1 é igual a média do ano 2, ou seja, estatisticamente os dados dos diferentes anos são iguais; e/ou (2) H1:Média do ano $1 \neq$ Média do ano 2, ou seja, a média dos anos são diferentes, ou seja, estatisticamente os dados dos diferentes anos são diferentes. A tabela abaixo sintetiza esses testes:

Tabela 4 - Teste Te Z: comparação de mesclas/híbridos/mistos nos quatro anos

\begin{tabular}{ccccc}
\hline Comparações & Média & Teste $-\mathrm{t}^{*}$ & Teste $-\mathrm{z}^{*}$ \\
\hline A-1 & 12 & 0,2495 & 0,2242 \\
A-2 & 8,87 & $0,0001^{*}$ & $0,0000^{*}$ \\
\hline A-1 & 12 & $0,0000^{*}$ & $0,0000^{*}$ \\
A-3 & 1,08 & $0,0007^{*}$ & $0,0000^{*}$ \\
\hline A-1 & 12 & 0,50 & $0,0000^{*}$ \\
A-4 & 0,87 & $0,0001^{*}$ & 0,2004 \\
A-3 & 1,08 & 0,2142 & \\
\hline A-2 & 8,87 & 0,50 &
\end{tabular}

Fonte: elaboração própria.

* Para valores menores que 0,05 rejeitamos $\mathrm{H} 0$, ou seja, existe diferença significativa entre as médias.

Nos dois testes, os totais de mesclas/híbridos/mistos encontrados nos anos A-1 e A-2 são iguais. O mesmo ocorre quando comparados os anos A-3 e A-4. Contudo, existe diferença significativa quando comparados A-1 e A-3, A-1 e A-4, A-2 e A-3 e A-2 e A-4. Esses dados quantitativos indicam, fortemente, que as mesclas/híbridos/mistos são, sobretudo, uma característica dos enunciados produzidos nos dois primeiros anos de escolarização (juntos, em termos percentuais, os dados do primeiro e do segundo ano somam 93,76\% dos dados encontrados). Indicam, também, que existe uma ruptura do segundo para o terceiro ano de coleta: uma queda brusca da quantidade de ocorrências. Essa ruptura aponta para uma 
mudança importante na relação criança-escrita - que praticamente deixa de ser afetada pelos processos linguísticos, enunciativos e/ou discursivos colocados em relevo pelas mesclas/híbridos/mistos.

\section{Considerações finais}

Neste artigo, o objetivo geral foi entender o que mesclas/híbridos/ mistos poderiam representar para a escrita da criança e, consequentemente, para a chamada aquisição da escrita. Esse objetivo geral desdobrou-se em dois objetivos específicos, por meio dos quais buscou-se: (1) compreender como funcionavam essas segmentações e (2) descrever como ocorreria sua emergência no período de escolarização correspondente à primeira etapa do Ensino Fundamental.

Com relação ao primeiro objetivo específico, foi possível averiguar, por meio de análise qualitativa, que essas segmentações raras e idiossincráticas têm funcionamento complexo, resultante de um jogo entre irrupção e interrupção de práticas orais e letradas, definidas aqui como experiências sócio-históricas que chegam a criança como memórias - no sentido de Pêcheux (1997, p. 56). Esse funcionamento complexo verificado em todas as mesclas/híbridos/mistos identificadas no material permitiu concluir que essas segmentações especiais são pistas das movências de sentidos e da própria língua atuantes na enunciação escrita da criança, movências permitidas pelos intricados e sempre inéditos encontros entre o eu e outro, constitutivos desse modo de enunciação.

Com relação ao segundo objetivo, foi possível descrever, por meio de uma análise quantitativa, como ocorria a emergência das mesclas/híbridos/ mistos no período de escolarização correspondente à primeira etapa do Ensino Fundamental. Todos os dados levantados por essa análise, tornaram viável uma principal (e importante) conclusão: a de que as segmentações classificadas como mesclas/híbridos/mistos constituem característica quase exclusiva do primeiro ciclo do EF-I, aparecendo apenas como resíduo nas etapas finais desse período de escolarização. Esse resultado confirma outros já encontrados na literatura nacional e internacional sobre o tema - por exemplo, Cunha (2010), em estudo semi-longitudinal, e Piacente e Querejeta (2012), em estudo transversal-correlacional.

Para finalizar, gostaria de ponderar sobre o impacto e as eventuais contribuições desta pesquisa para o campo de saberes no qual se inscreve 
- na área de ensino-aprendizagem de línguas e nos estudos sobre a escrita (em especial, sobre a escrita da criança).

Quanto ao impacto, ele já se mostrava, a meu ver, na proposição da pesquisa, uma vez que projetava como objeto, de forma relativamente inédita, um tipo bastante particular e quase residual de segmentação presente na escrita da criança, pouco estudado pelas pesquisas dedicadas à exploração do tema mais geral da segmentação na escrita, em razão, sobretudo, da raridade de seu aparecimento. Esse impacto se mostrou, também, pelo modo como diferentes quadros teóricos foram agenciados e correlacionados para descrever e explicar mesclas/híbrido/mistos. Ou seja, o impacto da pesquisa está relacionado à contribuição, em vários aspectos inédita, que fornece aos estudos sobre a segmentação da escrita da criança, mas, principalmente, ao estabelecimento e ao fortalecimento de uma perspectiva de análise desse tipo de dado, em particular, e da escrita da criança, de forma geral. Essa perspectiva funda-se, como adiantado e detalhado em outros trabalhos (CAPRISTANO, 2018), no entrecruzamento não simétrico de diferentes quadros teóricos, dentre os quais se destacam (1) quadros teóricos advindos do chamado núcleo duro da Linguística, ${ }^{12}$ operacionalizados, na análise, como forma de auxiliar na descrição de mesclas/híbridos/mistos; e (2) quadros teóricos de base enunciativa-discursiva, organizadores da análise e da reflexão feita na pesquisa.

Como consequência do estabelecimento e do fortalecimento dessa perspectiva de análise, outro impacto está relacionado a constatações, já feitas em outros trabalhos, sobre segmentação: elas não são meros erros ortográficos ligados à complexidade linguística e/ou gráfica envolvida no estabelecimento da fronteira de palavras ou meras evidências de como paulatinamente as crianças reconhecem limites de palavras escritas. Obviamente, essa é a face com a qual esses dados se mostram para o pesquisador e professor num primeiro momento; seu funcionamento, no entanto, não se restringe a essa sua dimensão. Quando se considera a escrita da criança, trata-se, como tentei demonstrar neste artigo, menos de "encontrar limites de palavras" e mais de

\footnotetext{
${ }^{12}$ Refiro-me, em especial, às propostas de descrição e de explicação do que se entende como o componente fonológico da linguagem (ou das línguas naturais) e das interfaces que, nessas propostas, esse componente estabeleceria com os demais componentes (morfológico e sintático, por exemplo), como as propostas de Nespor e Vogel (1986), sobre a organização prosódica da linguagem.
} 
"alçar-se e/ou encontrar-se com os sentidos da/para a (sua) escrita". Nesse alçamento, nos (não) limites da palavra - aqui entendidos como limites não óbvios, opacos, não transparentes - a criança move-se pelo e no modo de enunciação escrito, não exatamente recortando palavras, mas, sim, buscando encontrar sentidos da/para a (sua) escrita.

Quanto às contribuições, resta dizer que, apesar de a pesquisa ter caráter predominantemente descritivo e seus resultados não terem consequências didáticas diretas e óbvias, voltadas para o ensino e a aprendizagem da escrita, ela foi desenvolvida tendo esse ensino e essa aprendizagem como norte e fundamento, ou seja, embora, inicialmente, a pesquisa não tenha se proposto discutir o ensino e a aprendizagem da escrita, é supondo a existência e a relevância desses processos que se fez a descrição do trânsito da criança que pôde ser visto (que se mostrou, portanto) quando ela segmentou seus enunciados escritos e, nesse movimento, produziu mesclas/híbridos/mistos. Essas descrições, portanto, visam a impactar, positivamente, a compreensão do funcionamento da escrita da criança e essa visada certamente contribui, mesmo que de forma indireta, com elementos para se pensar na manutenção ou na mudança de políticas públicas voltadas para os anos iniciais de escolarização, nos quais a preocupação com o ensino e a aprendizagem da escrita é bastante presente.

Para mencionar apenas um exemplo, os resultados quantitativos alcançados com esta pesquisa trazem uma importante contribuição para as políticas públicas no que se refere à constatação de que as segmentações classificadas como mesclas/híbridos/mistos são, de fato, raras - resultado já insinuado em outras pesquisas sobre escrita da criança, mas, aqui, comprovado de forma efetiva - e constituem característica praticamente exclusiva do primeiro ciclo do EF-I - que, atualmente, é formado pelo que outrora corresponderia ao último ano do período pré-escolar e pelas antigas primeira e segunda séries do ensino fundamental. Esse resultado pode ser um elemento a indicar - junto, obviamente, com outras variáveis - a necessidade da manutenção e do aperfeiçoamento do sistema de ensino e de aprendizagem por ciclos, ${ }^{13}$ sistema que, pelo menos discursivamente, estaria comprometido, dentre outras coisas, com a valorização das experiências de

\footnotetext{
${ }^{13}$ Para uma discussão sobre o sistema de ciclos, conferir, como ponto de partida, o trabalho de Barretto e Mitrulis (2001) e, para uma revisão de literatura, o trabalho de Mainarde (2006).
} 
vida e dos saberes dos alunos e com a organização do tempo e do espaço escolar em conformidade com essas experiências e saberes.

Os dados de mesclas/híbridos/mistos levantados e examinados na pesquisa indicam, de forma clara, uma mudança bastante significativa na relação criança/escrita - portanto, numa das dimensões das experiências de vida e dos saberes dos alunos - do segundo para o terceiro ano de coleta, que corresponde justamente à fronteira entre o primeiro e segundo ciclos do EF-I.

\section{Agradecimentos}

Agradeço ao Manoel Luiz Gonçalves Corrêa, pela cuidadosa supervisão de todo o trabalho de pós-doutorado, à Giordana França Ticianel, por gentilmente ter auxiliado na primeira identificação dos dados, à Luciani Ester Tenani, pelos comentários generosos sobre os dados levantados na pesquisa e ao Lourenço Chacon, pela leitura atenciosa da versão final deste artigo.

\section{Referências}

BARRETTO, E. S. S.; MITRULIS, E. Trajetória e desafios dos ciclos escolares no país. Estudos avançados, São Paulo, v. 15, n. 42, p. 103-140, 2001.

BISOL, L. Constituintes prosódicos. In: BISOL, L. (Org.). Introdução a estudos de fonologia do português brasileiro. Porto Alegre: EDIPUCRS, 1996. p. 247-261.

CAPRISTANO, C. C. Segmentação na escrita infantil. São Paulo: Martins Fontes, 2007a.

CAPRISTANO, C. C. Mudanças na trajetória da criança em direção à palavra escrita. 2007b. Tese (Doutorado em Linguística Aplicada) - Instituto de Estudos da Linguagem, Universidade Estadual de Campinas, Campinas, 2007b.

CAPRISTANO, C. C. Por uma concepção heterogênea da escrita que se produz e que se ensina na escola. Cadernos de educação, Pelotas, v. 1, n. 35, p. 171-193, 2010.

CAPRISTANO, C. C. Um entre outros: a emergência da rasura na aquisição da escrita. Linguagem em (dis)curso, Tubarão, v. 13, n. 3, p. 667-694, 2013.

CAPRISTANO, C. C. A escrita da criança: da palavra alheia à palavra própria. In: SALEH, P. B. O.; COSTA-HÜBES, T. C. (Org.). O lugar da subjetividade no ensino da lingua(gem). Campinas: Mercados de Letras, 2018. p. 133-164.

CHACON, L. Constituintes prosódicos e letramento em segmentações nãoconvencionais. Letras de hoje, Porto Alegre, v. 39, n. 3, p. 223-232, 2004.

CHACON, L. Instabilidades da linguagem: discurso, lingua e suas relações. 2017. Tese (Livre-Docência em Linguística em Fonoaudiologia) - Faculdade de Filosofia e Ciências, Universidade Estadual Paulista, Marília, São Paulo. 2017. 
CHACON, L. Erros ortográficos e características da sílaba na escrita infantil. In: CORRÊA, M. L. G. (Org.). Pôster acadêmico: é possível ensinar sem modelo? Produção, avaliação e crítica. Campinas: Mercado de Letras, [2020?]. No prelo.

CORRÊA, M. L. G. Letramento e heterogeneidade da escrita no ensino de português. In: SIGNORINI, I. (Org.). Investigando a relação oral/ escrito e as teorias do letramento. Campinas: Mercado de Letras, 2001. p. 135-166.

CORRÊA, M. L. G. O modo heterogêneo de constituição da escrita. São Paulo: Martins Fontes, 2004.

CORRÊA, M. L. G. Heterogeneidade da escrita: a novidade da adequação e a experiência do acontecimento. Filologia e linguística portuguesa, São Paulo, v. 8, p. 269286, 2006.

CORREAA, M. L. G. Pressupostos teóricos para o ensino da escrita: entre a adequação e o acontecimento. Filologia e linguística portuguesa, São Paulo, v. 9, p. 201211, 2007.

CORRÊA, M. L. G. As perspectivas etnográfica e discursiva no ensino da escrita: o exemplo de textos de pré-universitários. Revista da Abralin, v. 10, n. 4, p. 333-356, 2011.

CORRÊEA, M. L. G. Bases teóricas para o ensino da escrita. Linguagem em (dis)curso, Tubarão, v. 13, n. 3, p. 481-513, 2013.

CUNHA, A. P. N. As segmentações não-convencionais da escrita e sua relação com os constituintes prosódicos. Cadernos de educaşão, Pelotas, v. 35, p. 323-358, 2010.

FERREIRO, E.; TEBEROSKY, A. Psicogênese da lingua escrita. Porto Alegre: Artes médicas, 1979.

MAINARDE, J. Organização da escolaridade em ciclos no Brasil: revisão da literatura e perspectivas para a pesquisa. Educação e Pesquisa, São Paulo, v. 32, n. 1, p. 11-30, 2006.

NESPOR, M.; VOGEL, I. Prosodic phonology. Dordrechet: Foris publications, 1986. PÊCHEUX, M. O discurso: estrutura ou acontecimento. Campinas: Pontes, 1997. PIACENTE, T. QUEREJETA, M. La separación de palabra en la escritura infantil. Revista Neuropsicologia Latinoamericana, [s. l.], v. 4, n 1, p. 1-17, 2012.

SERRANI, S. M. Transdisciplinaridade e discurso em linguística aplicada. Trabalhos em linguistica aplicada, Campinas, v. 16, p. 39-46, 1990.

SIGNORINI, I.; CAVALCANTI, M. C. (Org.). Linguística aplicada e transdisciplinaridade: questões e perspectivas. Campinas: Mercado de letras, 1998.

Data de submissão: 17/02/2020. Data de aprovação: 08/03/2021. 